\title{
Interfacial heat transfer behavior at metal/die in finger-plated casting during high pressure die casting process
}

\author{
Wen-bo Yu ${ }^{1,2}$, Song Liang ${ }^{3}$, Yong-you Cao ${ }^{1,2}$, Xiao-bo Li,2, Zhi-peng Guo ${ }^{1,2}$, ${ }^{1, S h o u-m e i ~ X i o n g ~}{ }^{1,2}$ \\ 1. School of Materials Science and Engineering, Tsinghua University, Beijing 100084, China \\ 2. Laboratory for Advanced Materials Processing Technology, Ministry of Education, Tsinghua University, Beijing 100084, China \\ 3. Beijing Star Airlines Mechanical and Electrical Equipment Company, Beijing 100074, China
}

\begin{abstract}
Heat transfer at the metal-die interface has a great influence on the solidification process and casting structure. As thin-wall components are extensively produced by high pressure die casting process (HPDC), the B390 alloy finger-plate casting was cast against an H13 steel die on a cold-chamber HPDC machine. The interfacial heat transfer behavior at different positions of the die was carefully studied using an inverse approach based on the temperature measurements inside the die. Furthermore, the filling process and the solidification rate in different finger-plates were also given to explain the distribution of interfacial heat flux $(q)$ and interfacial heat transfer coefficient $(h)$. Measurement results at the side of sprue indicates that $q_{\max }$ and $h_{\max }$ could reach $9.2 \mathrm{MW} \cdot \mathrm{m}^{-2}$ and $64.3 \mathrm{~kW} \cdot \mathrm{m}^{-2} \cdot \mathrm{K}^{-1}$, respectively. The simulation of melt flow in the die reveals that the thinnest $\left(T_{1}\right)$ finger plate could accelerate the melt flow from $50 \mathrm{~m} \cdot \mathrm{s}^{-1}$ to $110 \mathrm{~m} \cdot \mathrm{s}^{-1}$. Due to this high velocity, the interfacial heat flux at the end of $T_{1}$ could firstly reach a highest value $7.92 \mathrm{MW} \cdot \mathrm{m}^{-2}$ among the ends of $T_{n}(n=2,3,4,5)$. In addition, the $q_{\max }$ and $h_{\max }$ values of $T_{2}, T_{4}$ and $T_{5}$ finger-plates increase with the increasing thickness of the finger plate. Finally, at the rapid decreasing stage of interfacial heat transfer coefficient $(h)$, the decreasing rate of $h$ has an exponential relationship with the increasing rate of solid fraction ( $f$ ).
\end{abstract}

Key words: high pressure die casting (HPDC); interfacial heat transfer behavior; metal/die interface; solidification speed; solid fraction

CLC numbers: TG146.1 5 Document code: A Article ID: 1672-6421(2017)04-258-07

$\mathrm{H}$ igh pressure die casting (HPDC) is extensively used for mass production, due to the high productive efficiency of a desired component in a rapid solidification speed ${ }^{[1,2]}$. When HPDC molten alloy is injected into a relatively cold cavity of a die, the solidification rate is highly dependent on the interfacial heat transfer behavior in both the die and the molten alloy ${ }^{[3]}$, and subsequently influences the microstructure and the consequent mechanical properties of the final product ${ }^{[4-7]}$. In other words, a proper high cooling rate could favor the formation of fine microstructure in produced castings. Otherwise, too rapid a cooling rate could cause the premature solidification of the molten metal before the filling completion.

Many studies have been carried out to investigate

\section{*Shou-mei Xiong}

Male, Ph.D. Professor. His research interests mainly focus on $\mathrm{Al}$ and $\mathrm{Mg}$ alloys, high pressure die casting and simulation.

E-mail: smxiong@tsinghua.edu.cn

Received: 2016-10-09; Accepted: 2017-03-06 the interfacial heat transfer behavior at the metal-die interface, which can be characterized by an interfacial heat flux $(q)$ and an interfacial heat transfer coefficient $(h)^{[3,8,9]}$. Especially, after the emergence of new numerical approaches associated with inverse heat conduction problems, the interfacial heat transfer coefficient has been shown as a function of casting pressure, injection velocity and initial die temperature ${ }^{[10-13]}$. For example, El-Mahallawy et al. reported that a further increase after a certain value in the applied casting pressure would scarcely change the thermal field and the heat flux ${ }^{[14]}$. Guo et al. pointed out that the influence of the pressure would only be prominent if the casting step is sufficiently thick for a step-shape casting ${ }^{[15]}$. Dour et al. reported that a higher velocity always leads to a higher heat transfer coefficient and heat flux ${ }^{[16]}$. Furthermore, Papai, et al. found that the peak value of heat flux or heat transfer coefficient decreases as the initial die temperature increases ${ }^{[17]}$.

Recently, by using a special temperature sensor unit developed by Tsinghua University ${ }^{[18]}$, the influence of 
runner system type, as well as the influence of casting geometry and processing parameters on the interfacial heat transfer coefficient (IHTC, $h$ ) during HPDC were investigated ${ }^{[19,20]}$. It was found that the evolution of the interfacial heat transfer coefficient can be divided into four stages: namely the initial increasing stage, the high value maintained stage, the rapid decreasing stage and the low value maintained stage. For the finger-shape B390 alloy casting, the cover-plate AM60B alloy casting and the stepshape ADC12 alloy casting, the process parameters such as casting pressure and rapid shot velocity only have a secondary influence on the interfacial heat transfer coefficient peak values in comparison to that of the initial die temperature.

However, until now, no work has been carried out to investigate the distribution of IHTC in the flow gate area and overflow launder area in the finger-plate casting. Considering that many thin-wall components are produced by HPDC ${ }^{[21]}$, the five finger-plate B390 alloy castings were used to study the interfacial heat transfer behavior between the metal and die. The distribution of interfacial thermal coefficients, the filling sequence in finger plates, the solicitation rate and the evolution of solid fraction with different thicknesses were all studied and discussed in detail.

\section{Experimental procedure}

\subsection{Temperature measurements}

The experimental procedure is schematically shown in Fig. 1. The experiments were performed using B390 alloy on a TOYO
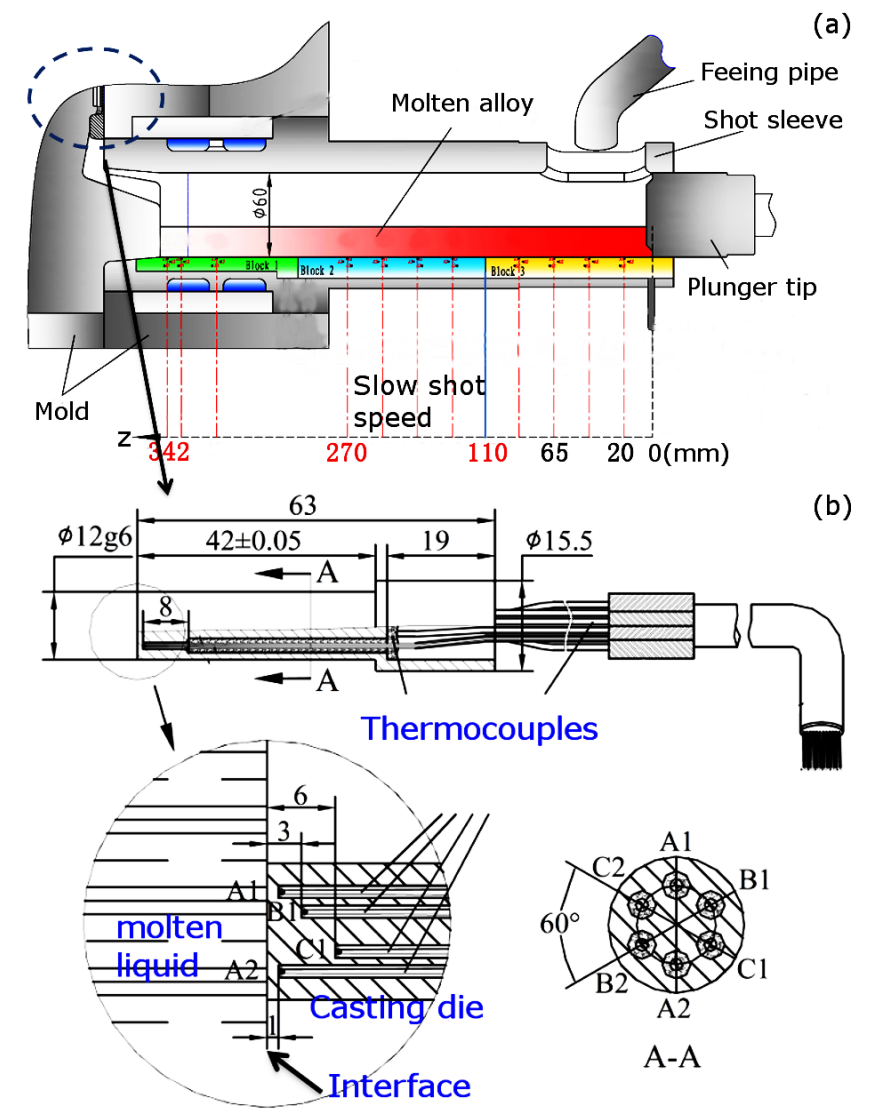

A-A

Fig. 1: Schematic description of experimental setup of shot sleeve and temperature measurement details about metal/die (length unit is $\mathrm{mm}$ )

Table 1: Chemical composition of B390 alloy and H13 steel (wt.\%)

B390

\begin{tabular}{|c|c|c|c|c|c|c|c|c|}
\hline Si & $\mathrm{Cu}$ & $\mathrm{Fe}$ & $\mathrm{Zn}$ & Mn & Mg & $\mathbf{N i}$ & Sn & Al \\
\hline 16.54 & 4.63 & 0.68 & 0.82 & 0.14 & 0.58 & 0.05 & 0.06 & Bal. \\
\hline C & Mn & Si & $s$ & $\mathbf{P}$ & $\mathrm{Cr}$ & Mo & v & $\mathrm{Fe}$ \\
\hline 0.396 & 0.36 & 0.94 & $<0.005$ & $<0.025$ & 5.05 & 1.25 & 0.82 & Bal. \\
\hline
\end{tabular}

350 ton die casting machine with H13 steel die (Table 1). During the HPDC process, the plunger first moved with a slow shot speed of $0.2 \mathrm{~m} \cdot \mathrm{s}^{-1}$ from $200 \mathrm{~mm}$ to $310 \mathrm{~mm}$ under a filling ratio of $18.0 \%$. Subsequently, for pushing the melt into the die cavity, the plunger moved at $1.75 \mathrm{~m} \cdot \mathrm{s}^{-1}$ in the rapid shot stage for the remaining length of the shot sleeve. At $330 \mathrm{~mm}$, the casting pressure was increased to $70 \mathrm{MPa}$.

Six thermocouples were inserted and welded inside of a H13 steel block (the chemical composition is same as the die), as can be seen in Fig. 1 (b). Six thermocouple probes were placed with three different distances from the metal/die interface: $1 \mathrm{~mm}$ $(\mathrm{A} 1, \mathrm{~A} 2), 3 \mathrm{~mm}(\mathrm{~B} 1, \mathrm{~B} 2)$ and $6 \mathrm{~mm}(\mathrm{C} 1, \mathrm{C} 2)$. Each of these thermocouple probes were sheathed with $0.5 \mathrm{~mm}$ in diameter and $0.045 \mathrm{~mm}$ in wire diameter. Real-time temperature data were then recorded using Spartan data logging system (96 isolated analog inputs channels) manufactured by the Integrated Measurement Corporation with a sampling rate of $500 \mathrm{~Hz}$.

Figure 2 (a) illustrates the five die casting finger-plate pieces. The thicknesses of the finger-plate castings are $1.27 \mathrm{~mm}$,
$2.54 \mathrm{~mm}, 3.81 \mathrm{~mm}, 5.08 \mathrm{~mm}$ and $6.35 \mathrm{~mm}$, respectively. To investigate the influence of metal liquid flow on the interfacial heat transfer behavior, the temperature measurements were carried out at two ends of each finger-plate in the 30th casting cycle. Their corresponding positions are also marked in Fig. 2. Labels $\mathrm{F}$ and $\mathrm{G}$ represent the overflow launch position and flow gate, respectively.

\subsection{Description of calculation}

The heat transfer coefficient was determined using an inverse method. This has been described in detail in Ref. [20]. The thermal properties of these materials are summarized in Table 2.

\section{Results and discussions}

\subsection{Application of inverse method at T4G and T3G}

Figure 3 shows the calculated and measured results of interfacial heat flux $(q)$ and interfacial heat transfer coefficient $(h)$ of B390 

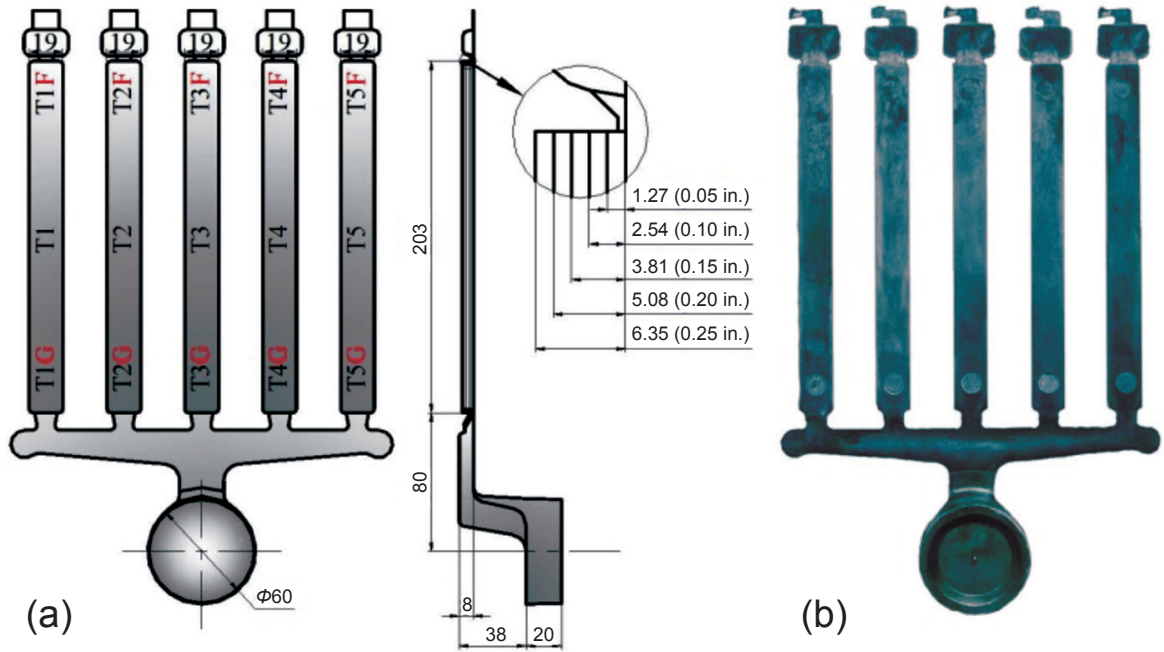

Fig. 2: Finger-shaped casting: (a) Configuration with dimension, (b) As-cast specimen

Table 2: Thermal properties of related materials

\begin{tabular}{ccc} 
Thermal properties & B390 & H13 \\
\hline Thermal conductivity, $\Lambda\left(\mathrm{W} \cdot \mathrm{m}^{-1} \cdot \mathrm{K}^{-1}\right)$ & 116.7 & $31.2-0.013 \mathrm{~T}^{\mathrm{a}}$ \\
Specific heat, $C_{p}\left(\mathrm{~J} \cdot \mathrm{kg}^{-1} \cdot \mathrm{K}^{-1}\right)$ & 851 & $478-0.219 \mathrm{~T}$ \\
Density, $\rho\left(\mathrm{kg} \cdot \mathrm{m}^{-3}\right)$ & 2693 & $7730-0.24 T$ \\
Solidus temperature, $T_{\mathrm{S}}\left({ }^{\circ} \mathrm{C}\right)$ & 505 & 1471 \\
Liquidus temperature, $T_{\mathrm{L}}\left({ }^{\circ} \mathrm{C}\right)$ & 650 & 1404 \\
Latent heat, $L_{\mathrm{s}}\left(\mathrm{J} \cdot \mathrm{kg}^{-1}\right)$ & 389,000 & 209,350
\end{tabular}

a- $T$ stands for the numerical value of temperature.

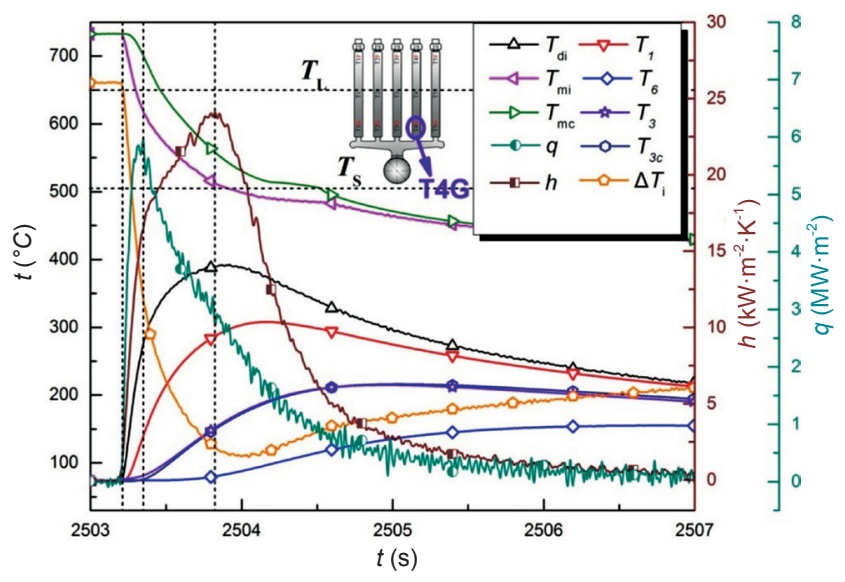

Fig. 3: Typical calculated and measured results at T4G position during the 30 th cycle

alloy obtained at T4G position, where $T_{\mathrm{di}}, T_{\mathrm{mi}}$ and $T_{\mathrm{mc}}$ are the temperatures of the die surface, the plate piece surface and center; $T_{1}, T_{3}, T_{6}$ are measured temperatures at 1,3 and $6 \mathrm{~mm}$ distanced from the metal/die interface; $h$ is the interfacial heat transfer coefficient; $q$ is the interfacial heat flux density; $T_{3 \mathrm{c}}$ is the calculated temperature in the die at $3 \mathrm{~mm}$ from the interface; $\Delta T_{\mathrm{i}}$ is the interfacial temperature difference between metal and die. The measured temperature curves of $T_{3}$ and calculated $T_{3 \mathrm{c}}$ are overlapped. This well overlapped result indicates that the application of the inverse method was successful in this study. When the molten metal contacted the relatively cold die surface, the temperature of the molten metal surface $\left(T_{\mathrm{mi}}\right)$ dropped from $730{ }^{\circ} \mathrm{C}$ to liquidus line $650{ }^{\circ} \mathrm{C}$ in $0.092 \mathrm{~s}$ with a cooling rate of about $869.5^{\circ} \mathrm{C} \cdot \mathrm{s}^{-1}$. This cooling rate is about 2.5 times of that obtained in ADC12 step-shape casting ${ }^{[19]}$. Meanwhile, the die surface temperature $\left(T_{\mathrm{di}}\right)$ increased and the maximum interfacial heat flux $\left(q_{\max }\right)$ increased to a peak value of $5.97 \mathrm{MW} \cdot \mathrm{m}^{-2}$. At this moment, $T_{\mathrm{mi}}$ still located between liquidus and solidus temperatures, which is about $618^{\circ} \mathrm{C}$. This suggests that no tight interface formed due to the flow of molten metal in the die; the interfacial heat transfer coefficient $(h)$ increased slowly. When $T_{\text {mi }}$ dropped to solidus temperature $\left(505{ }^{\circ} \mathrm{C}\right)$, the solid fraction reached $88 \%$ and the interfacial temperature difference between metal and die $\left(\Delta T_{\mathrm{i}}\right)$ decreased to $121{ }^{\circ} \mathrm{C}$. The $h$ value reached a peak of $24.08 \mathrm{~kW} \cdot \mathrm{m}^{-2} \cdot \mathrm{K}^{-1}$. Then, as the $q$ value decreased quickly and the difference in temperature at metal/die interface $\left(\Delta T_{\mathrm{i}}\right)$ increased, the $h$ value dropped quickly until the complete solidification of the plate piece.

Figure 4 shows the results of interfacial heat flux $(q)$ and interfacial heat transfer coefficient $(h)$ of B390 alloy obtained at $\mathrm{T} 3 \mathrm{G}$ position. The curves of $q$ and $h$ exhibit the similar trend at $\mathrm{T} 3 \mathrm{G}$ position as at $\mathrm{T} 4 \mathrm{G}$. However, the temperature of molten metal surface $\left(T_{\mathrm{mi}}\right)$ dropped from $730{ }^{\circ} \mathrm{C}$ to liquidus line 650 ${ }^{\circ} \mathrm{C}$ in $0.058 \mathrm{~s}$ with a cooling rate of about $1,379.3^{\circ} \mathrm{C} \cdot \mathrm{s}^{-1}$. This value is about 1.6 times of that obtained at T4G. Furthermore, when $\Delta T_{\mathrm{i}}$ decreased to $52{ }^{\circ} \mathrm{C}$, the $h$ reached a peak value of 64.3 $\mathrm{kW} \cdot \mathrm{m}^{-2} \cdot \mathrm{K}^{-1}$. This value is about 2.67 times of that obtained at T4G. As can be seen in Fig. 2, because T3G is located closer to the gating system, the pressure-transfer path can be easily formed and maintained. According to the previous report ${ }^{[20]}$, a higher casting pressure can enhance the contact between the casting and the die, which could directly lead to a higher $h$ peak value.

\subsection{Distribution of interfacial heat flux and interfacial heat transfer coefficient at different positions}

Figure 5 shows the results of interfacial heat flux $(q)$ and interfacial 


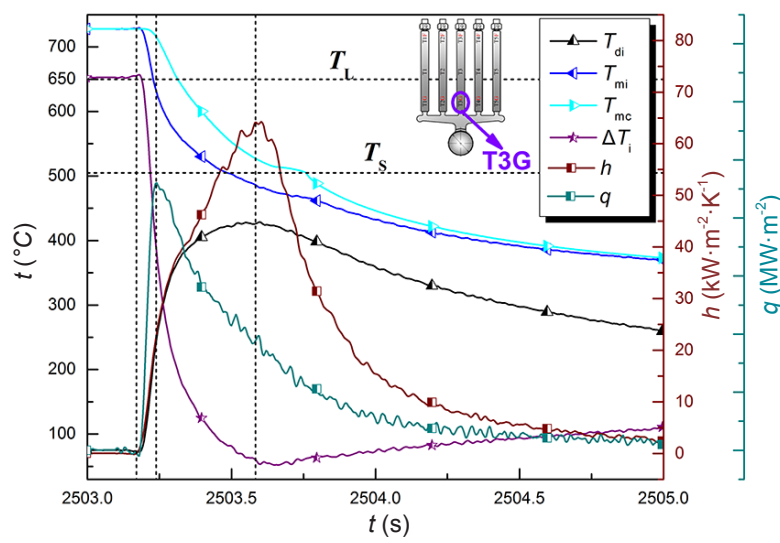

Fig. 4: Typical calculated and measured results at T3G position during the 30th cycle heat transfer coefficient $(h)$ obtained at $\mathrm{T} n \mathrm{G}$ and $\mathrm{T} n \mathrm{~F}$ positions $(n=1,2,3,4,5)$. As in the previous report in step-casting ${ }^{[20]}$, the thinner the thickness of plate finger, the slimmer its corresponding IHTC profile. In addition, the time for $h$ to maintain a higher value grows with the increasing plate finger thickness except for T3 case. The $q_{\max }$ and $h_{\max }$ with their corresponding response times are summarized in Table 3. For convenience, the temperature response time as the molten metal firstly reached the $\mathrm{T} 3 \mathrm{G}$ position was regarded as 0 . Concerning the area near flow gate, $q_{\max }$ and $h_{\max }$ values increased with the increasing thickness of finger plate except for the case of T3G. As T3G is located nearest to the sprue, the molten metal firstly reached here and $q$ firstly increased to the peak with a highest value $9.2 \mathrm{MW} \cdot \mathrm{m}^{-2}$. However, at the area near overflow launder, $q$ at T1F firstly reached the peak with a highest

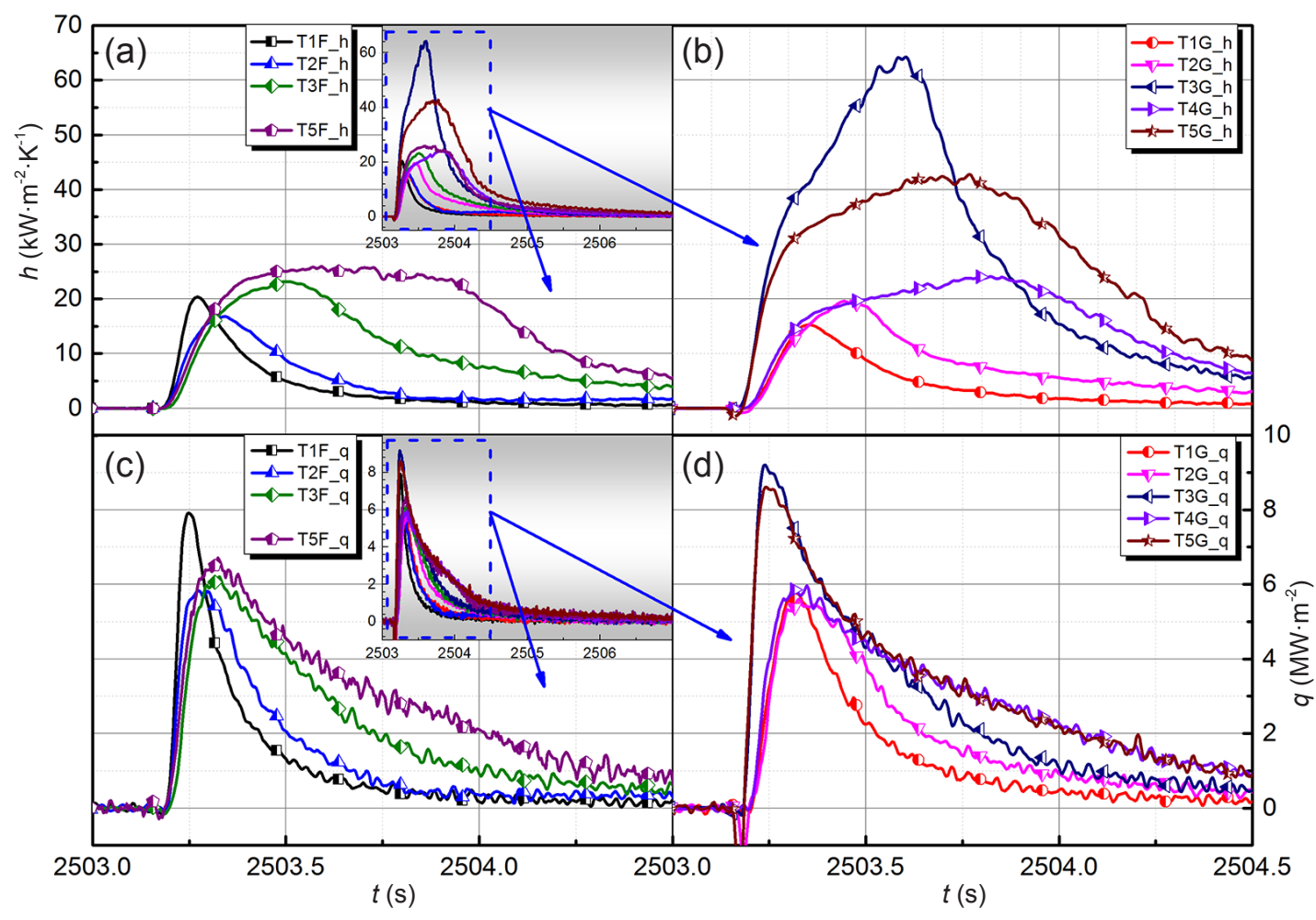

Fig. 5: Variation of interfacial heat transfer coefficient $(h)$ and interfacial heat flux density $(q)$ at two positions in each finger plate: Near over flow launder $(F)$ and near flow gate $(G)$

value $7.92 \mathrm{MW} \cdot \mathrm{m}^{-2}$, higher than T3F. In addition, the lowest $q_{\max }$ was found in both $\mathrm{T} 2 \mathrm{~F}$ and $\mathrm{T} 2 \mathrm{G}$ positions. To further investigate the reason resulting in this distribution of $h_{\max }$ and $q_{\max }$ in the finger-plate casting, simulation for the filling process of the melt was carried out, as shown in Fig. 6.

Figure 6 shows the filling process of the melt in the fingerplate die cavity at different filling ratios obtained by CAD/ CAE system ${ }^{[22-24]}$. The differences can be clearly found among different fingers, especially between $T_{1}$ and $T_{3}$ fingers. At the beginning, the molten metal flowed into the sprue at a speed of $50 \mathrm{~m} \cdot \mathrm{s}^{-1}$. Due to the geometrical location, molten metal firstly reached T3G position. However, as the thickness of $T_{1}$ is much thinner than $T_{3}$, the simulation result indicates that the metal liquid was accelerated to $110 \mathrm{~m} \bullet \mathrm{s}^{-1}$ from $50 \mathrm{~m} \bullet \mathrm{s}^{-1}$ in $T_{1}$ finger plate. Then the molten metal firstly reached T1F position. As a result, $q$ at T1F firstly reached the peak value $7.92 \mathrm{MW} \cdot \mathrm{m}^{-2}$, which is the highest among all of TnFs. According to Dour et al. ${ }^{[16]}$, a higher velocity always leads to a higher heat flux. This trend was also observed by Guo et al. ${ }^{[20]}$ and Hamasaiid et al. ${ }^{[8]}$. They explained that this effect is mainly caused by the in-cavity pressure arising from the high speed melt impact on the die surface. Furthermore, it can be seen that the filling processes of $T_{2}, T_{4}$ and $T_{5}$ were similar. Hence, their $q_{\max }$ and $h_{\max }$ were mainly influenced by the thickness of finger plate, i.e., the $q_{\max }$ and $h_{\max }$ increased with the increasing thickness of finger-plate.

\subsection{Interfacial heat transfer behavior at rapid decreasing stage}

To investigate the variation of $h$ with time at rapid decreasing stage, we fitted the results at rapid decreasing stage as shown in Fig. 7 and obtained the following equation:

$$
h=h_{0}+A_{\mathrm{h}} \times \exp \left(k_{\mathrm{h}} t\right)
$$


Table 3: $q_{\max }$ and $h_{\max }$ with their corresponding times

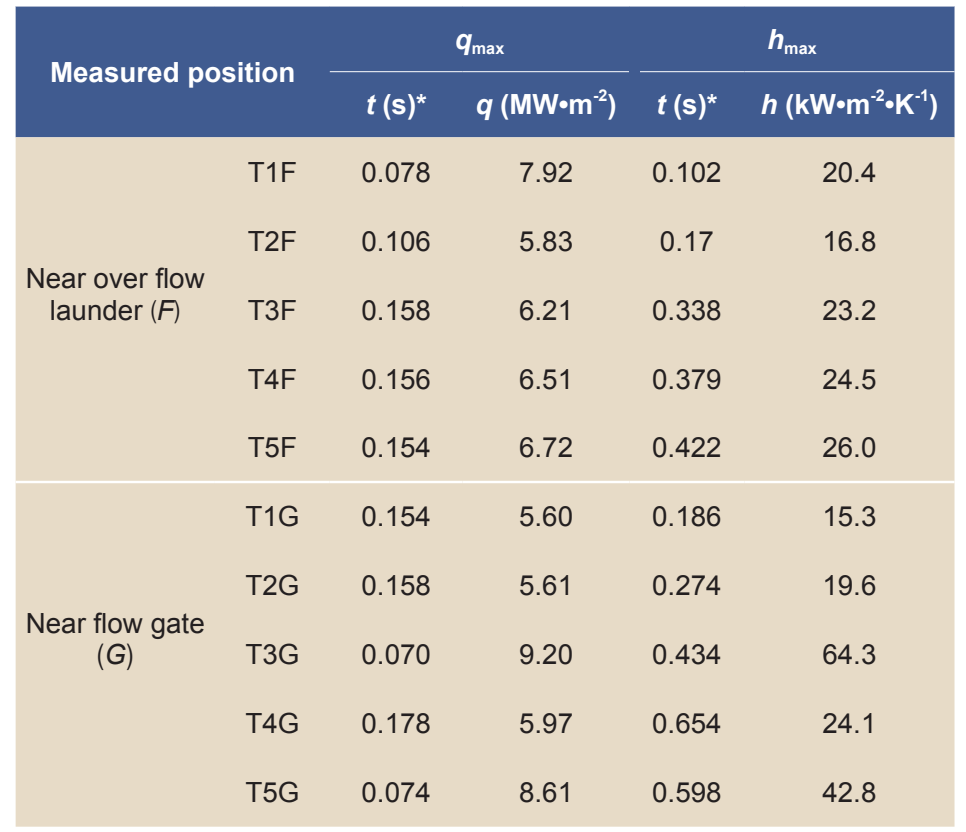

where $h_{0}, A_{\mathrm{h}}$ and $k_{\mathrm{h}}$ were constants, these values varied with different curves.

It is supposed:

$$
\theta_{h}=h-h_{0}
$$

where $\theta_{h}$ represents the difference between $h$ at one time and $h_{0}$.

With the substitution of Eq. (2) into Eq. (1) and following differentiation, we obtained

$$
\frac{\mathrm{d} \theta_{h}}{\mathrm{~d} t}=k_{h} \theta_{h}
$$

Equation (3) indicates that the decreasing rate of $h$ at one time is proportional to the relative magnitude of corresponding $h$. The value of $h$ decreased with time at the rapid decreasing stage. According to Equation (3), the decreasing rate of $h$ also decreased with time. In addition, the decreasing rate of $h$ increased with the increasing thickness of finger plate at rapid decreasing stage except for $\mathrm{T} 2 \mathrm{G}$.

*-The response time $(2503.170 \mathrm{~s})$ at T3G position was regarded as $t=0 \mathrm{~s}$

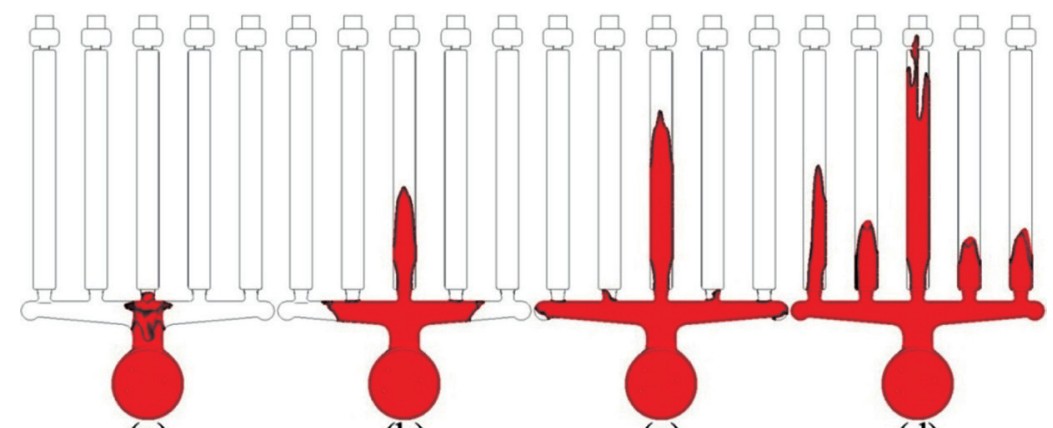

(a) (c)

(d)

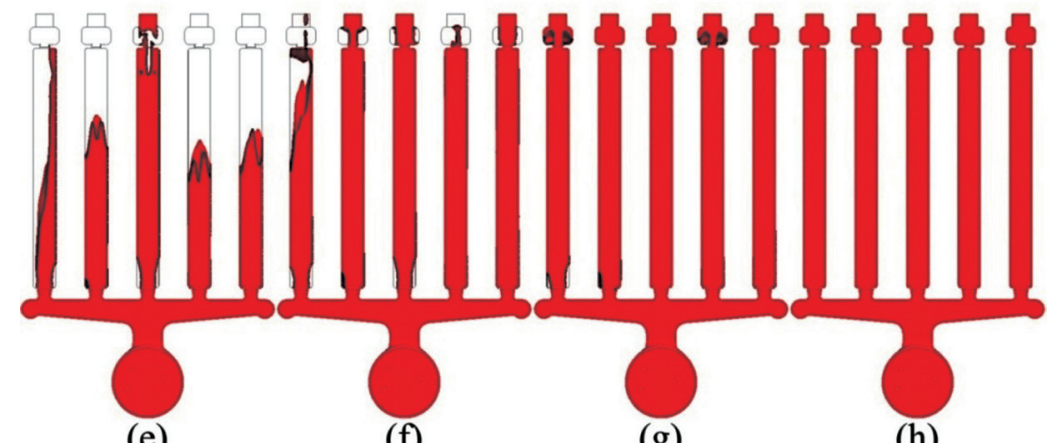

(e)

(f)

(g)

(h)

Fig. 6: Filling process of melt in finger-plate die at different filling ratios: (a) $45 \%$, (b) $50 \%$, (c) $55 \%$, (d) $65 \%$, (e) $75 \%$, (f) $50 \%$, (g) $95 \%$, (h) $100 \%$

Furthermore, the change of solid fraction as a function of time was also studied and is given in Fig. 8. The solidification rate was the highest at $\mathrm{T} 1 \mathrm{~F}$ and $\mathrm{T} 1 \mathrm{G}$ due to the minimum thickness of $\mathrm{T} 1$ plate, and the lowest solid fraction rate occurred at T2G. According to Fig. 6, the temperature at $\mathrm{T} 2 \mathrm{G}$ decreased slower than the other fingers, therefore, the solid fraction rate at $\mathrm{T} 2 \mathrm{G}$ is the lowest among all the fingers.

According to Fig. 6, $T_{1}$ finger plate was filled last. Herein, T2G area should be influenced by the melt flow movement from the sprue into $T_{1}$ finger plate. Due to this melt flow, the temperature at T2G decreased slower than the other fingers. Finally, the solid fraction rate at $\mathrm{T} 2 \mathrm{G}$ is the slowest among all of the fingers.

Similarly, we fitted the results in Fig. 8 and obtained the following equation:

$$
f_{\mathrm{S}}=f_{\mathrm{S} 0}+A_{f} \times \exp \left(k_{f} t\right)
$$

where $f_{\mathrm{S} 0}, A_{f}$ and $k_{f}$ were constants, these values varied with different curves.

It is supposed:

$$
\theta_{f}=f_{\mathrm{S}}-f_{\mathrm{S} 0}
$$

where $\theta_{f}$ represents the difference between $f_{\mathrm{S}}$ at one time and $f_{\mathrm{S} 0}$ 

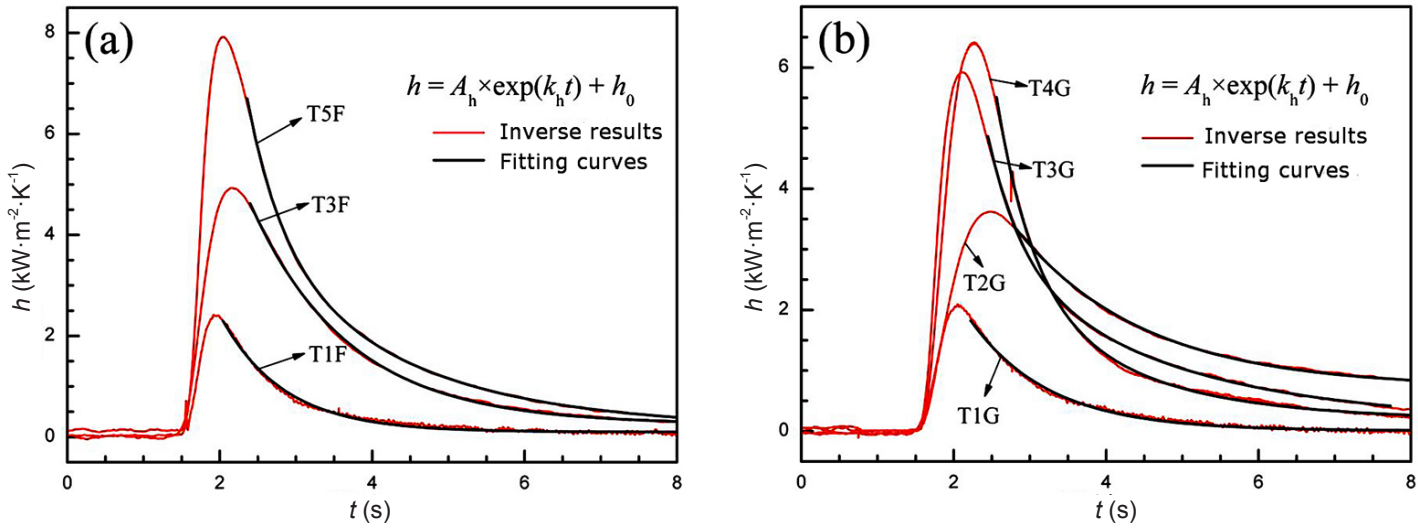

Fig. 7: Fitting results of decreasing rate of $h$ with time at rapid decreasing stage: (a) area close to overflow launder, (b) area close to flow gate

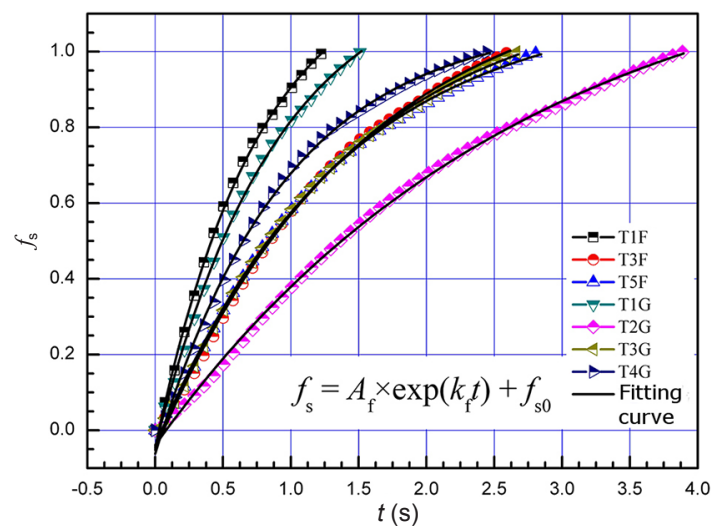

Fig. 8: Change of solid fraction as a function of time

obtained in fitting results.

With the substitution of Eq. (5) into Eq. (4) and the following derivative, we obtained:

$$
\frac{d \theta_{f}}{d t}=k_{f} \theta_{f}
$$

With combination of equation (3) and equation (6), we obtained:

$$
\frac{d \theta_{h}}{\theta_{h}}=\frac{k_{h}}{k_{f}} \frac{d \theta_{f}}{\theta_{f}}
$$

As $f$ increased with time and $h$ decreased with time, the fitting parameters $A_{f}$ and $A_{h}$ are negative and positive, respectively. Then the following equation was obtained:

$$
\theta_{h}=k_{h-f}\left(-\theta_{f}\right)^{\varepsilon}
$$

where $k_{h-f}$ is a constant and $\varepsilon=\frac{k_{h}}{k_{j}}$.

Equation (8) shows that the decreasing rate of $h$ has an exponential relationship with the increasing rate of $f$ at rapid decreasing stage of $h$. Furthermore, this quantitative analysis indicates that the molten metal solidification state and the interface heat transfer behavior are interdependent with each other.

\section{Conclusions}

A finger-plate casting was used and the die-casting experiment was performed by casting B390 alloy against an H13 steel die using a cold-chamber high-pressure die-casting machine. Based on our results, the following conclusions can be drawn:

(1) At the area close to the flow gate, $q_{\max }$ and $h_{\max }$ values increased with the increasing thickness of finger-plate except for the case of $T_{3}$. As $\mathrm{T} 3 \mathrm{G}$ is the nearest to the sprue in all of $\mathrm{T} n \mathrm{G}$, $q_{\max }$ and $h_{\max }$ at T3G could reach the highest value of $9.2 \mathrm{MW} \cdot \mathrm{m}^{-2}$ and $64.3 \mathrm{~kW} \cdot \mathrm{m}^{-2} \cdot \mathrm{K}^{-1}$, respectively.

(2) The movement of the melt in the finger-plate casting was simulated. The thinnest $T_{1}$ finger plate could accelerate the melt from $50 \mathrm{~m} \cdot \mathrm{s}^{-1}$ to $110 \mathrm{~m} \cdot \mathrm{s}^{-1}$. Due to this high velocity, $q$ at T1F firstly reached the peak value $7.92 \mathrm{MW} \cdot \mathrm{m}^{-2}$, which is higher than the other cases. In addition, the filling rate in $T_{2}, T_{4}$ and $T_{5}$ finger-plates were very similar. In this way, the factor of finger plate thickness dominated the variation of $q_{\max }$ and $h_{\max }$.

(3) At the rapid decreasing stage of $h$, the decreasing rate of $h$ increased with the increasing thickness of the finger plates except for $T_{2}$. Just as the lowest decreasing rate of $q$ at $\mathrm{T} 2 \mathrm{G}$, the lowest solid fraction rate occurred at $\mathrm{T} 2 \mathrm{G}$. It was found that the melt movement at $\mathrm{T} 2 \mathrm{G}$ area did not stop until the ultimate filling process of T1 finger plate completed. Due to this effect, T2G location could maintain a high temperature.

(4) The analysis demonstrated that the decreasing rate of $h$ has an exponential relationship with the increasing rate of $f$ at rapid decreasing stage of $h$. This suggests that the molten metal solidification state and the interface heat transfer behavior are interdependent with each other.

\section{References}

[1] Niu X, Hu B H, Pinwill I, et al. Vacuum assisted high pressure die casting of aluminium alloys. Journal of Materials Processing Technology, 2000, 105(1): 119-127.

[2] Aghion E and Bronfin B. Magnesium alloys development towards the 21st century. In: Materials Science Forum, Trans Tech Publ., 2000.

[3] Long A, Thornhil D, Armstrong C, et al. Determination of the heat transfer coefficient at the metal-die interface for high pressure die cast AlSi9Cu3Fe. Applied Thermal Engineering, 2011, 31(17): 3996-4006.

[4] Laukli H, Graciotti A, Lohne O, et al. The effect of solidification of metal prior to injection in HPDC on the grain size distribution in a complex die casting. Nadca Transactions, 2002, 21: 1-4. 
[5] Wang B S and Xiong S M. Effects of shot speed and biscuit thickness on externally solidified crystals of high-pressure die cast AM60B magnesium alloy. Transactions of Nonferrous Metals Society of China, 2011. 21(4): 767-772.

[6] Li X, Xiong S M, and Guo Z. On the porosity induced by externally solidified crystals in high-pressure die-cast of AM60B alloy and its effect on crack initiation and propagation. Materials Science and Engineering: A, 2015. 633: 35-41.

[7] Xu Qingyan, Feng Weiming, Liu Baicheng, et al. Numerical simulation of dendrite growth of aluminum alloy. Beijing, China: Science Press, Vol. 38, 2002: 5. (In Chinese)

[8] Hamasaiid A, Dour G, Dargusch M S, et al. Heat-transfer coefficient and in-cavity pressure at the casting-die interface during high-pressure die casting of the magnesium alloy AZ91D. Metallurgical and Materials Transactions A, 2008, 39(4): 853-864.

[9] Dargusch M S, Hamasaiid A, Dour G, et al. The Accurate Determination of Heat Transfer Coefficient and its Evolution with Time During High Pressure Die Casting of Al9Si3 $\mathrm{Cu}$ and Mg9Al1Zn Alloys. Advanced Engineering Materials, 2007, 9(11): 995-999.

[10] Nelson C. Nature of heat transfer at the die face. SDCE Paper No. 63, Detroit, Mich, 1970.

[11] Dour G, Dargusch M, and Davidson C. Recommendations and guidelines for the performance of accurate heat transfer measurements in rapid forming processes. International Journal of Heat and Mass Transfer, 2006, 49(11): 1773-1789.

[12] Beck J, Blackwell B, and Haji-Sheikh A. Comparison of some inverse heat conduction methods using experimental data. International Journal of Heat and Mass Transfer, 1996, 39(17): 3649-3657.

[13] Guo Zhipeng, Xiong Shoumei. Development of an inverse heat transfer model and its application in the prediction of the interfacial heat flux. Acta Metallurgy Sinica, 2007, 43(6): 607. (In Chinese)

[14] El-Mahallawy N A, Taha M A, Pokora E, et al. On the influence of process variables on the thermal conditions and properties of high pressure die-cast magnesium alloys. Journal of Materials Processing Technology, 1998, 73(1): 125-138.
[15] Guo Z P, Xiong S M, Liu B C, et al. Determination of the heat transfer coefficient at metal-die interface of high pressure die casting process of AM50 alloy. International Journal of Heat and Mass Transfer, 2008, 51(25): 6032-6038.

[16] Dour G, Dargusch M, Davidson C, et al. Development of a non-intrusive heat transfer coefficient gauge and its application to high pressure die casting: effect of the process parameters. Journal of Materials Processing Technology, 2005, 169(2): 223-233.

[17] Papai $\mathrm{J}$ and Mobley $\mathrm{C}$. Die thermal fields and heat fluxes during die casting of 380 aluminum alloy in $\mathrm{H}-13$ steel dies. In: Proc. NADCA Congress and Exposition, Detroit, 1991.

[18] Yu W, Cao Y, Li X, et al. Determination of Interfacial Heat Transfer Behavior at the Metal/Shot Sleeve of High Pressure Die Casting Process of AZ91D Alloy. Journal of Materials Science \& Technology, 2017, 33(1): 52-58.

[19] Guo Z P, Xiong S M, Cho S H, et al. Study on Heat Transfer Behavior at Metal/Die Interface in Aluminum Alloy Die Casting Process I. Experimental Study and Determination in the Interfacial Heat Transfer Coefficient. ACTA Metallurgica Sinica, 2007, 43(11): 1149. (In Chinese)

[20] Guo Z P, Xiong S M, Liu B C, et al. Effect of process parameters, casting thickness, and alloys on the interfacial heat-transfer coefficient in the high-pressure die-casting process. Metallurgical and Materials Transactions A, 2008, 39(12): 2896-2905.

[21] Ji S, Yan F, and Fan Z. Development of a high strength Al$\mathrm{Mg}_{2} \mathrm{Si}-\mathrm{Mg}-\mathrm{Zn}$ based alloy for high pressure die casting. Materials Science and Engineering: A, 2015, 626: 165-174.

[22] Zhang W, Xiong S M and Liu B C. Study on a CAD/CAE system of die casting. Journal of Materials Processing Technology, 1997, 63(1): 707-711.

[23] Jia L, Xiong S M, and Liu B C. Study on numerical simulation of mold filling and heat transfer in die casting process. Journal of Materials Science and Technology, 2000, 16(3): 269-272.

[24] Xiong S M and Liu B C. Study on numerical simulation of moldfilling and solidification processes of shaped casting. Chinese Journal of Mechanical Engineering, 1999, 12(1): 4-10. (In Chinese)

The research work was financially supported by the class General Financial Grant from the China Postdoctoral Science Foundation (No. 2015M580093), the National Nature Science Foundation of China (No. 20151301587) and the National Major Science and Technology Program of China (No. 2012ZX04012011). 